\title{
A SURVEY OF THE PRACTICE OF RISK MANAGEMENT IN WEST EUROPE COMPANIES'
}

\author{
by Roy Damary ${ }^{2}$
}

\section{Introduction}

This study is based on a series of personal discussions with the insurance or risk managers of some 80 large industrial companies in West Germany, France, U.K., Italy, Switzerland, Netherlands and Belgium. Its purpose is to present a view of risk management as it is practised in these companies.

Among interviewees there was some dichotomy between those who saw their task as centred on insurance and those who maintained that insurance was but part of their total armoury to deal with risk. But although the official stance of these two types of manager may be different, the difference in their work is not so extreme. The bulk of a "risk manager's" work is inevitably related to taking and administering insurance policies ; an "insurance manager" very commonly takes decisions about risk retention and is associated with risk reduction measures.

It is often suggested that increasing size of risks, reflecting increasing scale of production, more advanced technology and political instability, make the classical division between "pure risk" (a matter for the risk manager) and "entrepreneurial risk" (a matter for top management) disappear. This paper cannot pretend to reflect top managers' views because the interviews were not executed at that level. It does seem, however, reasonably certain that, while the introduction of "risk management" represents a major upgrading in the importance of the topic of risk, this topic is not yet an integrated part of senior management's preoccupations.

\section{Functions and responsiblilties}

Risk management may be defined as "the protection of a company's assets against loss or damage from pure hazard, in the most economic way possible". The term "pure" is used to denote risks of possible loss but no gain, thereby excluding entrepreneurial or conventional business risk, though making some allowance that pure risks are becoming more relevant in conditioning entrepreneurial risks.

This definition may be considered a little facile as it gives no feel of the nature of the work involved. We have therefore tried to divide the subject of risk management along four dimensions :

- the steps of risk management;

- the risks considered;

1 Undertaken by GIRA SA, Geneva, and sponsored by the International Association for Insurance Economics Research.

2 Director, Giraconsult, Geneva. 
- the area of decision-making involved;

- the part of the operation concerned.

Expansion of the subjects falling under these dimensions gives a listing as in Appendix I. The list is very long and immediately raises questions as to how much so many subjects can be dealt with by one person, even with assistance. A rather simpler way of viewing a risk manager is that he fulfils the functions of an insurance manager, together with some degree of responsibility for risk protection (the reduction or removal of risks), and operation of some method of self-retention of risks. The fact that this view suggests that risk management is an expanded version of insurance management is not a misrepresentation of the actual situation.

\subsection{The steps of risk management}

Yet another way of looking at risk management is to break down the stages of dealing with risk. The following describes these stages as described by interviewees.

Risk identification involves noting the presence and location of hazards. Ideally, all the types of risk listed in Appendix II should be covered by someone, if not the risk manager himself. The risk identified may be actual or potential (in the sense that the risk would be incurred if a certain action were taken). Some of the risks, notably fire, consequential loss (which can nearly always be bracketed with fire), transport and certain liabilities, can be identified with some precision, being associated, for example, with a particular building, contract or vessel. Others are of a more indefinable nature such as war, strikes or product liability.

Because so many different types of risk are involved, responsibility for their identification is usually widespread, usually falling on the shoulders of the manager most involved, be he, for example, a plant manager or a contracts manager. For the more obvious physical risks (i.e. something like fire or accident as distinct from risks arising out of contractual arrangements), outside inspectors of the broker and insurer are of great assistance, at the identification stage.

The existence of so many risks and of such different types implies that basic responsibility must lie with the line and staff managers associated with all the various parts of a company's operations. Such managers today would not typically reflect "responsibility for risk identification" in their formal job description and possibly not even in their attitudes. So here lies one of the main areas for improvement in risk management - engendering the right attitude among managers towards risk identification. One could imagine measuring or appreciating managers' attitudes towards risk, a sort of " risk management audit".

The evaluation of the risk involves an estimate of the probable and maximum loss patterns and of the probability of a loss (the latter may not be expressed mathematically). This step passes out of the hands of the operating manager and into that of the specialist. Since the insurance company needs the information as direct input into premium calculation, the insurer usually has the last say in risk evaluation. Nevertheless, some pre-evaluation is usually carried out by the insurance or risk manager, perhaps with help from his broker, both to help decide whether or not to place insurance and to verify that the insurance is adequate. 
Risk protection involves control of the risk through eliminating it, reducing its probability or limiting the probable loss. Eliminating the risk may involve a basic change in operations (e.g. discontinue manufacture of a product with a high risk of incurring liability) or transferring the risk through contractual arrangements (e.g. a penalty clause is negotiated with a supplier where delay in delivery would cause losses).

$35 \%$ of the insurance managers interviewed had clear responsibility for risk protection also. Nevertheless, the total risk protection effort was rarely under their responsibility and their task was one more of liaison with the safety department than being in charge of it. Safety officers (and we are using the term in the widest sense to include fire protection officers) were not perceived by insurance managers as having a job which involved decision making with a clear link to insurance. It was rather up to the insurance or risk manager to make the link where one was possible. The move towards improved safety that we encountered was mainly because of legal changes and by the desirability of safety in itself.

It was clear that the "total economic approach" to insurance and safety was rejected by interviewees ${ }^{3}$. According to this concept, all risk reduction, including human safety, has economic costs and benefits. "Logically", therefore, industrial companies should carry out cost/benefit analysis to decide just what level of safety they wish to aim at. However, our interviewees showed that this way of thinking was quite foreign to them. In addition, no interviewee had an explicit safety budget.

With the increasing size of risks, it is possible to speak in terms of a company being "vulnerable" to a loss in the sense that the occurrence of the loss would effectively cause the company to cease trading. Political risks, such as that of nationalisation, exposure to very high product liability claims, and the risk of losing the production of a key factory with no alternative means of compensating loss production, are all examples of risks that can enter the area of vulnerability.

In principle, the concept of vulnerability is that even satisfactory insurance cover is no real answer, so that risk protection becomes much more important than insurance. In practice, our interviewees showed negligible awareness of this concept and continued to concentrate their efforts on risks that were insurable. Risks entering the vulnerability area are not normally the responsibility of the risk manager. Such risks, together with uninsurable risks such as those associated with strikes, remain the responsibility of the Board. There is therefore a strong tendancy for all risk and insurance managers to classify risks in insurance terms and to deal directly with only those that are insurable. Although some risk managers would state that insurance "is but a small part of their task", in practice the link with insurance "thinking" remains extremely strong.

The decision on insurance is really one of deciding whether or not to transfer the risk to an insurer subject to the possibility of so doing, and the amount of risk that the company wants to retain. Of course, not all risks can be transferred in this way (e.g. strikes, war), or the premium is considered prohibitive (e.g. explosive factories).

3 The Fire Protection Association has made economic analyses in some depth, but in the specific field of fire control, not that of general safety at work. 
This responsibility may be fairly easy to centralise. The Board, usually through the financial director, can lay down basic guidelines with regard to the types of cover required, and the insurance or risk manager can then decide on the need to insure each individual case and the appropriate level of deductible to seek.

In two-thirds of our interviews, the insurance manager had this direct functional authority over insurance. In the other third, his role was more of an advisory nature, whereby individual division or plant managers would accept the responsibility to insure or not insure after at least seeking the advice of the insurance manager (centralised versus decentralised insurance).

In practice, the distinction between an advisory and an authoritative role is not very clear, as advice from an experienced insurance manager is usually respected as much as if it were a direct instruction.

The placing of insurance involves negotiation with the insurers (perhaps through brokers). Obviously, there is feedback here on the insurance decision since the availability of policies and their respective costs affect the final decision on non-insurance, acceptance of a deductible and the use of a captive.

This task is usually administered centrally by the insurance manager, though in some decentralised companies individual relations may be maintained at local plant level to ensure that the insurance companies involved are informed directly of changes with fire risk, etc.

In Europe there is a high level of loyalty to insurers so that insureds change their main insurer for each area only rarely, and then only in the event of extreme disagreement. Insureds typically emphasise that smooth personal relations and claims settling are worth more than shopping around for the lowest rate.

The amount of direct contact that an insured has with an insurer is, of course, very dependent on whether he uses a broker. Small and medium companies in most countries deal with brokers, but the practice among large companies varies greatly. In Germany, Switzerland and Italy, outside brokers are rarely used, whereas in France and Belgium brokers are nearly always adopted.

In the U.K., the situation is between the two extremes, with large industrial companies enjoying considerable freedom in choosing to use brokers or not. About $60 \%$ do choose to use brokers, at least for some services (see Table IV of Appendix I). We found some companies that wanted only certain advisory or administrative services from brokers and, to achieve this, came to some arrangement whereby the broker placed some of the insurance and, on the basis of the brokerage received thereon, supplied a certain service for many areas of risk. One interviewee remunerated his broker for such limited services on a fee basis, but generally brokers seem to resist this approach to remuneration.

Loss control is a step that comes into play after a loss has occurred. It involves minimising the effects of the loss. We did no discover specific responsibilities for this function amongst our interviewees except in one case.

For all others, de facto responsibilities fall on the shoulders of the operating managers affected by the loss. 
Contingency planning implies a provisional answer to the question "what would we do if such-and-such factory went out of action?" The usual answer to our question on contingency planning was that such plans were impossible given the continually changing market for the supply of materials. Nevertheless, $10 \%$ of our interviewees explained that they did encourage the establishment of contingency plans, with emphasis on availability of space in other plants of the company, the existence of makeshift equipment and, to a limited degree, the availability of chemical intermediates, etc., on the open market.

Loss assessment is the formal step of attributing a monetary value to a loss. It is usually left to insurance companies since an outside specialist (perhaps appointed by the insurance company) and the independence of an appointed assessor are appreciated.

Claims handling is the process of dealing with the details of having a loss reimbursed by the insurance company (or possibly by an internal fund). The function is usually carried out by the insurance manager or, if a broker is used, this would be part of the latter's responsibility.

It should be mentioned that the last two steps are frequently handled by independent loss adjustors, though there is more emphasis on their role in Anglo-Saxon companies than on the Continent. Their work includes the technical side of examining the cause of the loss, controlling it and recommending steps for future prevention, and the financial side in terms of deciding if the policy covers the loss and the proper amount to be paid out allowing for any average provision. Finally, they would establish if there was a case for recovery against third parties.

\subsection{Type of risk}

It would be quite inappropriate here to make a list of all types of risk and insurance covers that an insurance or risk manager must consider. We therefore merely mention those areas which seem to be of most concern to our interviewees.

It is clear that fire or explosion insurance is the dominant one, both in terms of its implications for premiums and for the effort required in risk prevention. Two main causes of fire may be separated and we return later in the report to the difference between them. On the one hand there are conventional fire losses arising from such matters as poor housekeeping, arson, etc., and which occur essentially to the building. On the other hand there are fires and explosions arising from the process or equipment itself.

Associated with fire or other losses of a production facility are the consequential losses. Consequential loss cover can be defined in a number of ways, but even in its developed form of "loss of profits", indemnity can never be complete, notably because absence from the market for many industrial companies means long-term damage to their market share and therefore their profitability over a long period. Insureds are aware that insurers cannot satisfactorily cover this risk, partly because of the imprecise nature of losses. Possible loss of market share is a powerful incentive to make companies think in terms of maximum risk protection rather than relying on insurance. 
Employers' liability. This is not a major preoccupation for insurance managers for the following reasons:

- the responsibility for safety at work is usually someone else's (the safety officer) who traditionally reports to the personnel department;

- the impulse towards improved safety is provided mainly by the laws of the land and moral ${ }^{4}$ considerations ;

- state social security schemes take over all or part of the insurance.

In cases where the insurance manager still has to purchase appreciable employer's liability cover, there is some motivation for him to improve claims performance because premiums are effectively "cost plus" for large organnisations. Nevertheless, only some $5 \%$ of our interviewees spent much effort on this question.

The legal system in the U.K., based on common law, makes this country somewhat different from the rest of Europe. It was said during interviews that most Unions in the U.K. put in a common law claim against employers for every accident, regardless of fault. The claims, generally for a few hundred pounds, provide additional compensation over and above the Social Security. Neither insurers nor employers are in the habit of defending the claims as court costs would exceed the amount of claim involved. In any case, there is the feeling that the courts are more and more predisposed to the employee, again regardless of fault (thus moving towards the U.S. position).

However, one British company interviewed said that it made a point of defending claims where it felt the employee was solely responsible. This was in the motive of discouraging frivolous claims and encouraging improved safety (other interviewees disagreed with the idea that safety standards drop because of the ease of obtaining compensation).

Other risks - public, product and professional liability, contractors all risks, infraction, fidelity, transport, political, civil commotion - all remain the responsibility of risk managers, but are more "standard" (except perhaps product liability for some) and take less of his effort than the above.

As already mentioned, risk managers, when defining areas of risk, inevitably express them in terms of insurance categories. This often reflects implicit acceptance of the present departmentalisation of insurance and slows down possible change in this regard. In some contrast to this, risk management consultants and academics would tend to associate risk management with "horizontalisation of risks, classifying them by degree rather than by nature.

The following chapter takes an approach based on areas of functional responsibility of an insured. The correspondance with insurance categories is rather low.

\subsection{Areas of decision-making}

This chapter is again based on a synthesis of interviews with insureds. Its main purpose may be taken as to demonstrate the decision-making process in industry and

4 i.e. that safety is desirable (almost) regardless of its cost. 
the way many individuals are concerned with a given risk, either explicitly or implicitly. It may be noted that no one individual can technically cope with the many disciplines involved.

The process or equipment design necessarily involves, as part of its engineering, consideration to avoidance of breakdown, and in particular catastrophic breakdown. The latter is particularly important in those industries (e.g. the chemical and oil industries) where the presence of dangerous substances, of high pressure or of high temperature, can give rise to the danger of fire and explosion. In such industries the steps of risk identification, evaluation and reduction can only be made by highly technical staff.

The introduction of fire risk reduction measures in building design is also technical, but is more readily understood by a layman. Typically, the considerations to be taken into account include the material of construction, the spacing of buildings, the installation of fire detection devices and sprinklers, internal fire walls and doors, adequate escape facilities, etc. The basic decisions here have to be made by the building and plant design team, although they can be open to suggestions from outsiders, for example, sprinklers engineers.

In these areas of process and building design, the responsibility for risk management was very vague in all our interviews, except those where we found a true "risk manager". Where there was no risk manager, the question of risk might not even be directly confronted by the investment committee, though, of course, the designers, etc., were bound to consider risk protection as part of their work, even if this term was not used.

Once a company's buildings and plant are in place, there is the question of continued surveillance to ensure that new risks do not appear or its prevention measures become ineffective. This work mainly involves inspection and correction, firstly of the risk reduction devices (sprinklers, fire extinguishers, detectors, escape routes) and secondly of modifications to existing plant or buildings. The second consideration is still essentially technical, but tends to be treated in a less formal manner than plant or building design.

Human safety involves considerations beyond the purely monetary loss created by employees losing time, their ability to work or their life. The main tasks involved in this area concern training personnel to be safety-conscious, and record-keeping so that effective counter-measures can be taken if one type of accident keeps recurring. Although human safety overlaps with fire prevention in, for example, teaching employees not to smoke in certain areas or not to leave oily rags lying around, the physical installations aimed at reducing fire are not usually the responsibility of the same person who is in charge of human safety.

All the above areas of decision-making are really concerned with fires or accidents at work. There are, in addition, a whole series of areas involving decisions outside the actual work place.

There are decisions with regard to the contracts or legal arrangements made by companies. It has to be quite clear who accepts liability in a contract, what limits 
there are to that liability, and where there is exposure by law quite independently of contract working. The skills required in these decision areas are, of course, legal skills.

Product design, including packaging, has rather obvious bearings on the risk a company runs with regard to product liability. This is again an essentially technical decision in which safety or reliability considerations are taken into account as one of several design criteria.

Production policy involves decisions with regard to how large individual production units should be, and where they should be located. Decisions here have to be almost always based on a compromise between lowering production costs by concentrating production and not running the risk of losing the entire production in the event of damage to the plant. Similarly, decisions with regard to production location based on local labour costs, nearness to raw materials or nearness to markets, might be affected by political risks arising in the country in question.

The question of employee screening, although delicate, can be extremely relevant where employees have access to vital information. It seems natural to check the background of employees that will be handling cash, but this seems to be relatively rarely done in the case of information. In any event, it can again be seen that the decision to be made here belongs to a specialist.

Finally, some interviewees mentioned labour relations, since in the context of a highly significant, uninsurable risk of strikes, few things can be so relevant. Decisions here can only be in the hands of the most senior management.

\subsection{Part of company's operations}

The fourth dimension of risk management is the part of the company's operations concerned. Five main areas of concern can be identified from our interviews :

- production units,

- transport function,

- offices,

- EDP centres,

- interface with suppliers, customers and third parties.

These areas require little further explanation. The key point to note is again the large number of people involved in risk management. For all these people, risk management is a small, usually unformalised, even unrecognised, part of their jobs.

The complexity of keeping contact with so many entities throughout an industrial organisation is the main reason why many insurance managers do not want to extend their task too much in the way that most people enbracing the term "risk manager" would wish to do. There is a paradox here that the co-ordination of decisions concerning risk is so complicated that any one person having the responsibility could only have functional responsibility therein and not line responsibility. On the other hand, some people see the task of co-ordination as simply too difficult for one person and throw the responsibility for risk manangement back into the line management structure. 


\section{Organisation}

\subsection{The risk manager}

In most companies, almost all the components of the various dimensions of risk management described in the above chapter are carried out somehow. It may therefore be appropriate to characterise risk management, not by the fact that the above components exist in a company, but that they are co-ordinated. A risk manager is therefore one person who ensures that the various decisions are made in all the areas and that authority is clearly defined.

Reconsideration of Appendix II shows that it is quite impossible for a risk manager to be solely responsible for all these matters. To have such responsibility he would need the skills of a process engineer, building designer, fire prevention engineer, safety officer, insurance manager, lawyer, product designer and detective, together with a number of skills normally found only in the top management of companies.

Therefore, in the language of organisational development, a risk manager has to be an "integrator". He has to make use of the skills of a large number of other people and has to influence events through his advice and moral authority rather than through formal authority. After all, if the risk manager were given authority in all the areas associated with risk management, he would, in fact, be managing director !

The above definition of a risk manager's job is more than that normally associated with insurance managers. The latter are traditionally concerned only with those steps of risk management from the decision about insurance onwards.

In practice, an insurance manager also has to liaise with other people, for example, the legal department with regard to contracts, and the fire protection department with regard to the cost and effectiveness of certain prevention devices. But. the key distinction between an insurance manager and a risk manager remains that the latter is responsible for the co-ordination.

During our study we sought a simple test to see whether an individual might best be described as a risk manager or an insurance manager. The simple test involved observing whether an individual was responsible for both the risk reduction and insurance. To be a "risk manager" an individual must meet this simple test, but meeting it does not necessarily make him a risk manager since he may be falling down in other regards.

Nevertheless, this simple test proved to be useful and applying it to our interviewees the breakdown is as reported in Table $I$ of Appendix $I$.

The companies where the "risk manager" was responsible for expanded safety duties but not insurance ( $6 \%$ of the sample) had relegated insurance to a very minor position. While some $38 \%$ of interviewees met our simple " test", only some $13 \%$ of them (all included in the $38 \%$ ) were actually entitled "risk managers".

\subsection{The risk management department}

Since the risk management function involves co-ordination of so many different parts of a company, it is questionable whether a risk manager should have anybody directly under him. There is no particular reason, for example, for either the insurance 
department or the safety department to be under him. The size of the risk management department is therefore no measure of its effectiveness.

Nevertheless, the risk manager usually has the insurance department directly under him, for the simple reason that most risk managers are "promoted" insurance managers or have been brought in from the outside to replace an insurance manager or, exceptionally, move in above him. Since insurance is one of the main tools of a risk manager, it seems reasonable to have this function under his line authority.

The same argument could be applied to that other mainstay of risk management - the risk protection. In practice, this responsibility is usually part of the "safety department". These departments can be very substantial in large companies and involve quite an "empire" in their own right. This is one reason why it is unusual for a safety department to be put under the authority of a risk manager.

The second reason why risk protection is usually not part of the authority of a risk manager is that risk managers tend to be insurance trained. They are unlikely to have a second full training in safety engineering or fire prevention. There is natural reluctance in companies to give the authority for a function to a staff person (as distinct from a director) who has not had a formal training in the field concerned.

While there are practical considerations for risk managers not usually to have the safety department directly under their authority, risk managers interviewed usually had some organisational procedure to facilitate co-ordination with the safety department. The simplest mechanism encountered was to have the two departments reporting to a common director. In this way the co-ordination was formalised and any disagreement could be rapidly dealt with by moving just one step up the line structure.

It must be admitted that this concept concerns only two aspects of risk management - insurance and the protection of fire and human safety risks. But just as we state that the responsibility for co-ordinating these two activities is a simple but effective test for defining someone as a risk manager, so it seems that if any one of the many integrating relationships need formalising, it should be this one.

\subsection{Liaison}

A risk or insurance manager is necessarily a staff rather than a line manager. His power and influence are therefore particularly dependent on those of the person to whom he reports (though the risk managers' personal integrative qualities remain key).

Almost all of the risk managers we encountered are "promoted" insurance managers, without change of reporting relationship. It is therefore appropriate to report on these relationships for all interviewees, be they risk managers or insurance managers.

Thus, excluding the few safety managers interviewed in companies where insurance was a minor function, the following results summarise our interviewees' reporting relationships :

- report to administrative director or company secretary $38 \%$

- report to financial director $45 \%$

- report to legal department ${ }^{5} \quad 9 \%$

5 Solution found only in Germany and Switzerland, where the legal department is also concerned with tax matters and therefore closely linked to finance. 
- report to chairman or Board as a whole

$4 \%$

- report to engineering/technical department

$4 \%$

The more influential risk managers were usually associated with the financial director. If a risk manager reports to the financial director, the direct link of risk management to financial results is naturally emphasised.

Liaison with most other parties concerned in risk management is one based on personality and willingness to go and see people.

Interviewees explained that no single test of the effectivenes of a risk manager can be better than observing how much he interacts with other people. It may be assumed that if he spends most of his time in his own office, seeing few other people in the company, he is not fulfilling the function of a risk manager. Frequent contacts are essential with local plant management and with the safety organisation (though we were astonished sometimes that the safety organisation was at a different floor of the building to the insurance manager and that they virtually never met).

It is quite clear that local plant managers have neither the time nor inclination to visit headquarters to see the risk manager. The risk manager must therefore visit them and, in the words of one of our interviewees, " the job requires lots of common sense and shoe leather".

This is where the style of the risk manager is so important. To be an effective risk manager involves more than a formal training in insurance and in risk improvement. He has to combine qualities of self-assurance with a modesty that will encourage other people in the company both to trust him and seek his advice. Thus there is an active component of continual liaison, combined with a general need to encourage managers to be more risk conscious.

We found that those individuals meeting our test of being a risk manager were generally in the first half of their working career and combined experience from both industry and the insurance world. They usually had not spent all their career in one company, but had perhaps changed positions every three to four years.

One interviewee explicitly stated that he thought it was good both for the individual risk manager and for his employer that he be replaced at intervals no longer than five years, so that a fresh look could be introduced to risk management practices from time to time.

\section{Politique}

\subsection{A framework for politique 6}

Within the very large number of components of risk management, there are two that stand out, viz. insurance and risk protection.

These two key components give a clue as to the possible policies that an industrial company can follow with regard to risk management. By emphasising one component or the other, companies can develop policies on a continuous spectrum.

6 We use the word "politique" instead of "policy" (in the meaning of "guideline to course of action") to avoid confusion with "insurance policy". 
At one end of the spectrum, the company obtains the widest insurance cover possible, seeks no deductibles and relies largely on the insurance company and brokers to provide the risk management advice. The company has a minimum safety organisation.

At the other end of the spectrum, the company has a large and powerful safety organisation, whose responsibilities cover all physical and human risks. The loss prevention performance of this company is so good that its average losses are only about $10 \%$ of those of its sector as a whole. The only insurance beyond those obligatory by law is one for catastrophic fire or natural disaster damage (excess-of-loss in the several millions of dollars). The insurance function, concerned with the obligatory insurances, is "forgotten" in low levels of the organisation. The excess-of-loss policy is, however, negotiated at highest levels. Within the company there is a system for making up losses in the short term - a sort of internal banking system.

Neither of these two extremes (and they are real companies) is particularly satisfactory from the point of view of the insurance industry. In the first example, the loss ratio tends to be so high that the insured is not a profitable client. In the second example, the insurers receive relatively little premium, although so far there have been no losses to pay.

Furthermore, in the first example the insurance companies have to spend considerable time and effort to convince the company to improve its performance, while in the second example the insurers meet the top management once a year and never even visit any of the sites.

\section{Graphical Representation of Risk Management Policies}

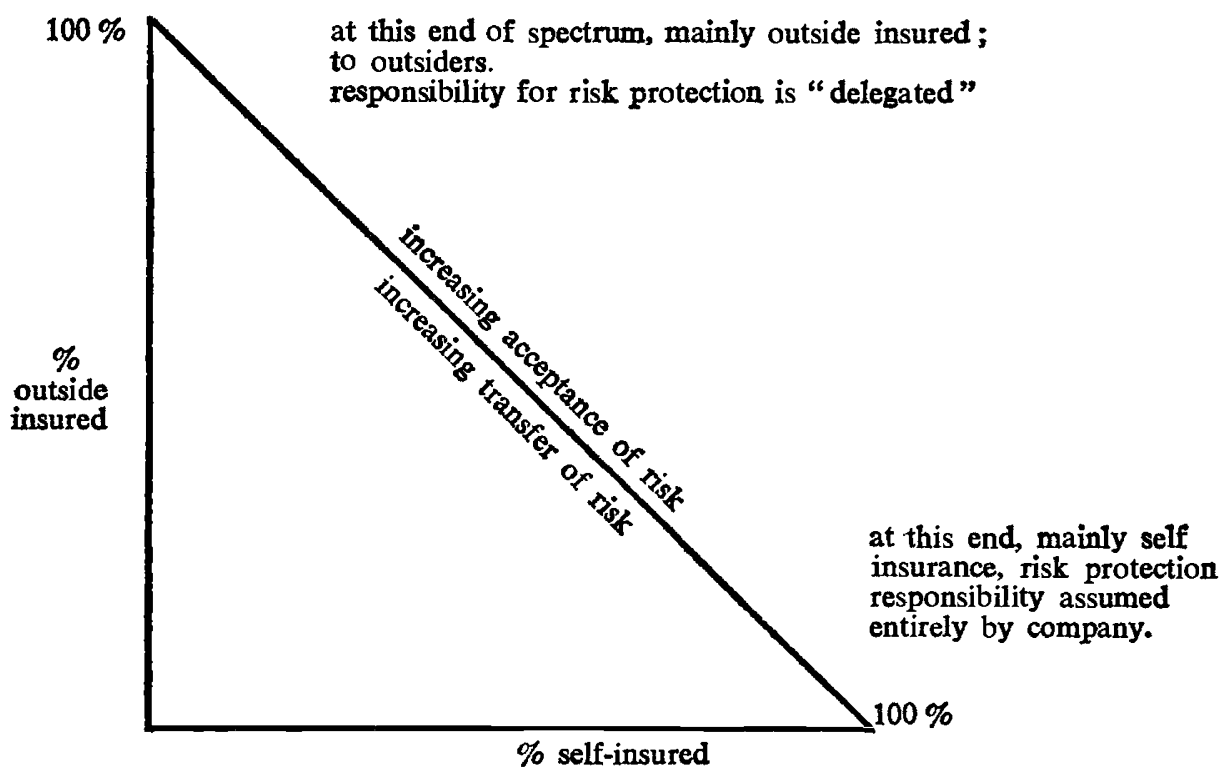


As may be expected with two such extremes, most companies fall somewhere inbetween. There is no general ideal compromise, but each company finds one corresponding to its style of management and past history.

As a company moves away from relying entirely on outside insurance (i.e. moves away from the left-hand side of the diagram), more of the direct responsibility is being accepted by the company itself. Indeed, it seems to be clearly understood by both industry and the insurance profession that risk management is essentially an industrial function. Outsiders, be they insurance companies, brokers or consultants, cannot take over the risk management function, they can only assist it and advise on it.

Implications of this for the insurance profession are at two levels :

- the insurance tools made available :

- advice rendered.

The first area of implication, that of the insurance tools offered, is the one where most of our interviewees concentrated their remarks about the insurance profession. Extracts from their remarks are included in chapter 4 below.

The second area of implication, that of advisory services, is more difficult to deal with because this is no longer a subject on which users express fairly clear needs and the insurance profession can decide either to meet these needs or refuse them. When it comes to advice, industrial companies have widely different attitudes as to whether or not they need any. Moreover, the sources of advice are manifold: insurance companies, brokers, risk management consultants, government organisations and industrial bodies. This issue is discused in chapter 5 below.

\subsection{Attitude of top management}

This study did not involve interviews with managing directors, but rather with insurance managers and financial or legal directors. Nevertheless, some reasonably clear ideas of the attitudes of top management about risk management and insurance can be deduced:

- in most companies insurance and risk protection are matters to be completely delegated;

- in companies where a politique of risk retention has been adopted, this is a matter where the financial director should act, to some extent, on his own initiative ; 7

- the lack of enthusiasm for highly protected risks found among insurance managers is a reflection of top management's attitude (particularly with regard to dislike of outside interference).

\subsection{Influence of size of company}

In practice, the most relevant measure of company size with regard to its attitude to risk management is the annual insurance premium (though logically it should be the size of risk which may not be quite the same thing). There is a lower limit to

7 But he can be counteracted by the Board. We had a case where the financial director was pleading for an extension of $C L$ cover, which was being refused by the Board. 
annual insurance premiums below which it is unlikely that a company would have an insurance manager. (It may be noted that the position of insurance manager itself was quite new, dating back, say, five to eight years in many of the companies interviewed.) In companies smaller than this, it is usual for insurance to be administered by the company secretary or his assistant secretary.

Whether a company had an "insurance manager" or a "risk manager" does not seem to be a function of size within our sample. Thus we found risk managers with annual premiums as low as $\$ 500,000$ (which is about the break-point between having and not having an insurance manager) and as high as $\$ 30$ million. But, the interest of medium and small companies in risk management is rather small.

If a company is very large (e.g. with a turnover of several billion dollars) there may be more difficulties in introducing risk management concepts than for companies with a turnover of, say, up to $\$ 500$ million. This is both because of difficulties of co-ordinating so much activity through one point and also because very large companies typically have built-in "empires". We found, for example, that some large companies have massive safety organisations, with perhaps scores of individual safety officers, safety handbooks, intensive poster campaigns, etc. It is exceedingly difficult in such cases for such a safety organisation to be made dependent on a risk manager or even for a fully satisfactory liaison between risk manager and safety department to be set up.

An interesting phenomenon we noticed during the study was that of individuals appointed as insurance managers, but with a vocation to introduce full risk management practice into the company. Generally, these individuals were either very patient or very frustrated, since introducing risk management, with its concomitant restructuring of responsibilities, is not something that can be done by an incumbent insurance manager with any speed. For example, he may point out that safety and insurance should be co-ordinated under one person. He may hesitate to propose that the one person should be himself - so unless someone on the Board pushes this theme for him, he is unlikely to receive much attention. In one case of our interviews, it was apparent that the insurance manager was also having difficulties in being taken seriously because he was still relatively young, a common characteristics of people with a full risk management approach.

In another interview case, the change had progressed quite well under the efforts of an incumbent insurance manager. But this man was older and the progress he had made had been achieved over a period of some eight years.

Examples of the successful introduction of risk management practices into a company suggest that, for any speed and effectiveness in bringing about change, new risk managers are needed perhaps with the departure of older staff. Active support from the Board, and not just acquiescence, is absolutely essential.

\subsection{Influence of multi-nationalism}

The first problem that occurs in multi-nationalism is that of co-ordination. The distance, language barriers, the imposition of local insurance rules, all combine to make the practice of international risk management much more difficult than on a national scale. 
In the case of U.K. companies interviewed, only $10 \%$ of our interviewees had international authority, though some international co-ordination usually remained. In Continental countries, the Netherlands was the only country where we found a really international approach to risk management.

The general absence of international risk management practice is due both to co-ordinating problems within companies and to the complications of international insurance. The greater difficulties are created by restrictions in certain countries with regard to placing insurance policies outside the country and to different rules for the setting up of policies. These types of constraint seemed particularly strong for fire insurance.

We discovered strong opinions among multi-nationals on the need for greater international standardisation and simplification : ideally world-wide cover on a single policy, with the appropriate degree of decentralised administration for inspection, risk assessment, etc.

\subsection{Influence of industrial sector}

There seems to be a distinction between "simple" industries and those where the processes used are inherently dangerous and complicated to understand. The chemical and oil refining industries are the most obvious examples. In other industries the product (rather than the manufacture) is inherently dangerous, e.g. aerospace and pharmaceuticals.

Thus industries with process or product-inherent risks can be contrasted with " simple" industries (with straight fire risks) such as food and drink, general engineering and even glass and aluminium manufacture. (Although there is much high temperature work in the last two instances, there is also a 24-hour surveillance and direct involvement of technical experts used to handling dangerous processes.)

If these two general classes of industry can be accepted, then it can be observed that in the "conventional fire risk" industries the risk manager and/or safety organistion can take direct responsibility for risk improvement, and, by extension, for most of the steps in the risk management chain, particularly those concerned with the identification and evaluation of risks.

On the other hand, the industries with process-inherent risks are too complex for there to be the requisite technical skills present in the risk manager or in his department. In these cases he can become far less involved in risk improvement and this responsibility has to fall mainly on the engineering and production departments of the company. It remains possible, of course, for him to affect the management attitude to safety, but this is likely to be quite high anyway.

A general rule can be established that the simpler the processes involved in an industry, the more direct power can and should be given to a separate safety organisation, whose main emphasis can then be on the reduction of fire risks.

Where large companies have different types of products and probably a divisionalised structure, more difficulties arise. The basic risk improvement needs of a company with, for example, a chemicals, a pharmaceuticals and a consumer products division, are quite different from one division to another. 
Both in the case of the multi-product company and the highly technological company, the demands on the risk manager as a co-ordinator are even greater, since it is clear he has to establish respect for himself even in areas where his technical competence is lacking.

Two industries stand out as putting product liability ahead of fire risks as the risk manager's main preoccupation, viz. aerospace and pharmaceuticals. Both of these industries run the risk of incurring very large individual claims in the event of product malfunction.

We discovered certain cases of dissatisfaction in the pharmaceutical industry over the way insurers were unable or unwilling to meet the required cover.

In the context of risk protection, much progress has already been made in instituting departments (particularly in the pharmaceutical industry) which track the history of products at all stages of development and marketing so that the company can react fast to any emergency that arises.

\section{Insurance tools used in risk management}

Here we are dealing with the insurance aspects of risk management as distinct from the risk protection aspects. The two main components of the insurance aspects are :

- obtaining the cover required;

- obtaining this cover as economically as possible.

A major issue for insureds, and one which is a matter of some discord between insurers and insureds, is that of self-insurance. The overall size of a company and the spread of the type of risk concerned can be such as to make a certain minimum annual loss "inevitable" - the "burning costs". It is this burning cost level of exposure that many insureds prefer to carry themselves to retain cash and reduce administrative expense. The discord arises from the fact that most insurers see these burning cost risks as a vital supply of information about loss occurrance, of risk spread and of statistical data.

\subsection{Non-insurance}

The simplest way to retain a risk is, of course, not to insure it. Almost all our interviewees indicated areas where insurance was available but where they had decided against taking out policies, e.g. burglary, damage to glass, office equipment, and perils. The other fact of this aspect of risk management is, however, that risk managers identify other, more serious risks, thereby increasing the degree of risk consciousness of the company.

Of greater significance is the decision to insure for consequential loss or not. Here the consideration against insurance is often the one that the conditions of cover are too difficult to apply. The $35 \%$ of our interviewees ${ }^{8}$ that did not use consequential

8 See also Table III in Appendix I. 
loss used the common argument that the company had several plants with overlapping production facilities, so that the loss of one part could be absorbed temporarily by other production units, with corresponding reductions in consequential losses. Interviewees that did take consequential loss cover tended to select only for parts of their production.

\subsection{Central funding}

It can be argued that the very term "sef-insured" implies, the setting up of a mechanism to pay for losses as and when they occur. In practice very few companies seem to set up any serious internal mechanism for covering losses. In fact, only three interviewees (all in the U.K.) stated that their companies had an explicit central fund into which those companies or divisions made payments in lieu of premium and against which losses could be charged without special permission from the financial director. In all other cases, non-insured losses were carried out of operating income, usually at divisional rather than central level.

The usual reason put forward for not setting up a central fund was that payments to the fund would not be tax deductible. (The Netherlands seems to be the only European country which does allow tax-deductibility for internal insurance funds.) In fact, of the three companies that did maintain central funds, one was in a situation of not paying tax anyway, the second closed out the funds at the end of every financial year and only the third accepted the consequences of having to pay tax on the reserve funds.

\subsection{Deductibles}

Deductibles may be imposed by the insurer for bad risks, or sought by the insured when he feels his risk is better than the average. As an insurance tool for risk management, we are concerned only with the latter situation. Deductibles are the basic corollary of a risk retention policy.

There seems to be no problem in obtaining deductibles of a small level and benefiting from a modest reduction in premium. $45 \%$ of our interviewees adopted such deductibles. There is a greater problem in finding a consensus opinion between insurers on the one side and insureds on the other, over what premium reduction fairly corresponds to a large deductible (i.e. of over $\$ 25000$ ).

When an industrial company opts for risk retention, deductibles can be used internally with regard to what losses are met by operating divisions and what by headquarters. However, most interviewees rejected the principle that a deductible could be used to improve risk performance within an industrial company, just as insurers showed no signs of being convinced that imposing deductibles was really a means of improving the risk performance of companies with poorer risk protection.

Opinions among the insureds interviewed were divided as to whether losses occurring within the deductible limit should be paid for by headquarters or divisions, with a small majority in favour of leaving payments to operating divisions. Two interviewees specifically recommend their division and plant managers to budget a modest level ( $f 5,000$ per year) of losses that might be expected to occur. 


\subsection{Captives}

As a very topical subject, the issue of forming a captive insurance company had been considered by nearly all of our interviewees. $24 \%$ of them had already formed captives and a further $13 \%$ stated that they had the intention of so doing.

Captives are, of course, insurance companies in their own right, but are owned by their major customer. Captives in Europe are by no means new (some are about 50 years old), but there has been great expansion in their numbers over the last decade. The recent ones have been set up almost always in countries where the rules for the operation of companies in general, and insurance companies in particular, are less strict than in the industrialised countries, and where there are usually tax and currency advantages. The Bahamas have been the centre, par excellence, for captives.

A distinction may be drawn between the motives in forming a captive and steps taken to ensure that, once the decision to forme a captive has been made, it is formed in the most economical way possible.

The basic reason given by our interviewees for having formed or being about to form a captive is a straight economic one. To them, the formation of a captive would allow yearly savings and expenses and also bring about cash flow advantages. Another way of saying the same thing is that the return on investment for forming a captive was sufficiently high to justify spending funds thereon. Companies can only be interested in a captive if they have a better than the average loss ratio.

Once this basic requirement had been met and companies were able to justify formation of a captive as an investment in itself, then the other considerations of tax savings and financial flexibility would come into play in deciding on the location of the captive.

\section{Sources and remuneration of service}

In the second part of Appendix II a list of insurance and risk management services is presented. When the total activities of a risk manager are considered, it is fairly clear that room remains for such outside advisory services. Below we consider just three sources of advice: brokers, risk manangement consultants and insurance companies.

But before considering the question of who does and can supply advisory services, there is the question of how they are financed. Here two opposite opinions can be identified. By far the more common one among our interviewees was that they could not accept the idea of paying a professional fee for services rendered. In fact, only $5 \%$ suggested that they would be prepared to pay such fees.

The opposite point of view was represented by just one interviewee, the risk manager of a French multi-national. His view was that the level and quality of service he required in his risk management function would involve costs beyond the funds available from either a broker's commission or an insurer's overhead. He wanted to separate out the fee for services, so that he could have more service, tailormade to his requirements. 
Now it should be noted that most insurance and risk managers have no experience of paying a professional fee for services rendered in such fields as auditing, management consultancy, market research, etc. Since separate fees for services rendered have not been a practice within the insurance industry, the institution of such a system cannot be envisaged by many people. The readers are invited to judge for themselves which of the above opinions has the greater insight.

An alternative to charging explicitly for additional service might lie in adopting a still more flexible approach to individual rating. For what must be considered mainly psychological reasons, insured seem to accept the idea of a special rate incorporated into a special service fee, while resisting the idea of an explicit service fee. Some American insurers make a practice of indicating on their fee the separate components of premium and service.

\subsection{Brokers}

For reasons associated with the historical development of the insurance industry and with the legislation in vigour, the position of brokers in European countries varies greatly from country to country. In France and Belgium virtually all users of insurance place their insurance through brokers and use brokers as a major source of advice. The extensive use of co-insurance in these countries has been cited as one reason for the strength of brokers there. Insureds trying to go direct would find it too complicated to deal with the many contacts required for each policy. Neither the insurers nor the insureds showed any sign of questioning the role of brokers in France and Belgium during our interviews.

In contrast, Germany is a country where brokers have often been eliminated from playing a role in the insurance of large industrial companies. Most large industrial companies have a captive broker with "Personalunion" with the insurance department of the company. Some of the captive brokers have several tens of employees. (There are also captive brokers in France, but they tend to be one-man companies designed to permit commission sharing on a legal basis.) So far as links with the insurer is concerned, the presence of a captive broker is no different from going direct. Premium and advice discussions are always directly between the insurer and the insured.

In Italy, the activities of brokers are a recent phenomenon. One insurance manager interviewed in Italy said he had been aware of their presence only from 1969. The same interviewee made a sharp distinction between local Italian brokers and the international brokers that have set up operations in Italy. The Italian insurance infrastructure is based on the use of agents, with each insurance company having several hundred "free agents" together with company-owned agents (essentially branch offices) in the major cities. All agents are compensated on a commission basis, but they are each linked to one insurance company, there being no question therefore of shopping around from one insurer to another.

Thus, as far as the above four countries are concerned, France and Belgium can be grouped as being very broker-dependent, while Germany and Italy play down the role of brokers, at least for large industrial companies.

The U.K. and the Netherlands lie somewhere inbetween. In these countries brokers are not protected either by legislation or by the complication of excessive co-insurance. 
However, they have always had a major role to play in historical terms, having grown up with the insurance profession. In fact, the insurance industry and broking developed side-by-side, each being very dependent on the other. In the Netherlands, there is some tendency to form captive brokers as in Germany, but our information on the Netherlands showed no real trend to question the utility of brokers. Only in the U.K. is their role seriously questioned by large industrial companies.

The date shown in Table IV of Appendix I apply to the insureds we interviewed in the U.K.

Amongst the full users of brokers we encountered two risk managers that seemed very anxious to begin dealing direct, but had opposition to this move from the top management of the company.

It can be concluded from the above that, as a large industrial company improves its risk management practice, the role of a broker is questioned, and in some cases his importance is greatly diminished. There is a powerful incentive for risk managers to go direct in that they can demonstrate that their salary has been paid for by commission savings.

Where insurers were continuing to use brokers fully or partially, they mentioned appreciation of the broker carrying out servicing of policies, notably in keeping them up to date and in handling claims. There was no emphasis in the U.K. put on the risk protection advisory services of brokers. This contrasts with out interviews in France where the advisory services of brokers were indeed emphasised more by insureds interviewed.

Brokers interviewed in the study emphasised that one of their major strengths was being able to obtain insurance at the best conditions both because of their total negotiating power (the portfolio of many clients) and because they know the market so well. British risk managers contacted seemed reluctant to admit this.

It would certainly be unwise for us to try and draw any conclusions about the future trend in the use of brokers, even in the U.K. Evidence is contradictory. For example, while the above suggests a slight move against brokers, the 1971 publication ${ }^{9}$ by the Corporation of Insurance Brokers gives a much more optimistic picture for the future role of brokers. All that can be said is that their role is being questioned, that the servicing rather than the placing function seems to be given more emphasis by large companies, and that some insurers and insureds would like to see the commission compensation system replaced by something more akin to a fee for services rendered. The question is: "should the prime object of brokers be only the placing of his client's business to the best of his ability?".

It is also clear that many "issues" concerned with providing advice, more sophisticated cover, international policies, etc., can frequently be dealt with either by the brokers or by the insurance companies. It is as if there were two separate sets of solutions to these issues raised, the one based on working through brokers, the other based on the insurance companies working out systems whereby insureds can go direct.

9 A Study of the Requirements, Internal Practices, Attitudes and Expectations of Insureds in Obtaining Insurance, July 1971, by the Economist Intelligence Unit. 
The very fact that in certain countries such as Germany and Italy the option of going through the brokers is effectively absent, means that, for all issues with international implications it will be far from easy for the insurance industry to find solutions.

\subsection{Risk management consultants}

As risk management consultants are seriously present in Europe only in the U.K., our comments concern mainly that country. None of the insureds interviewed indicated that they had used risk management consultants. Just two interviewees said they were likely to do so. From other sources, however, we were told explicitly that some of the companies interviewed had indeed been clients of a leading risk management consultancy. Thus there seems to be a certain reluctance to admit the use of risk management consultants.

Some interviewees, speaking of the usefulness of risk management consultants in a hypothetical way, admitted that they would be useful in terms of bringing a fresh look to review risk management policies. These statements were significant as they implied that the role of risk management consultants would be that of providing advice from time to time, advice in terms of a review of politique, and that risk management consultants are not expected to become advisors on a continual basis.

Whether or not final expression is through a formal risk management consultancy. there is some evidence that, in countries other than the U.K., pressures to create a form of risk management advice exist. Thus we have been told that a leading Swedish insurer invited a British broker to offer its risk management consultancy arm in Sweden. The insurer introduced the broker to its major clients.

Finally, we would note that a leading American broker has a "Fire Protection Consultant" arm operating on a separate fee-paying basis. Although they seem to decline use of the word "risk management", their description of service is, in fact, indistinguishable from that which would be offered by a formal risk management consultancy.

\subsection{Loss adjustors}

Since loss adjustors are intimately involved in examining the causes of losses, they inevitably build up a body of expertise in loss prevention. Now, since loss adjustors are paid a professional fee only when a loss has been incurred, they have, in principle, no interest in extending their service to loss prevention advice. However, under the pressure of their clients, and more long-term considerations, loss adjustors are now indeed beginning to offer this service. We have had information to this effect in a conference where a loss adjustor was emphasising the adjusting firm's pools of knowledge and also their ability to make sure that cover was adequate. Direct information from another loss adjustor demonstrated how it was essentially client pressure that was making them move into a service akin to risk management consultancy.

The ability of loss adjustors to provide loss prevention advice, both in processinherent risks and in conventional fire situations, re-emphasises the importance of the claims handling function as a source of information in building up a pool of knowledge 
about loss prevention. The applicability of this comment to loss adjustors is equally strong, of course, to the claims handling departments of insurers. We have been informed that some major American underwriters operating in Europe are stressing this particular aspect of their business.

\subsection{Insurance companies}

The level of service provided by insurance companies varies greatly from country to country, with particular dependency on whether or not brokers are commonly used. The U.K. insurers offer the widest range of services, with the greatest effort being on risk protection advice for fire and engineering risks. Yearly surveys are practised with emphasis on the physical aspects of the risk. These visits are quite major events and usually involve a tour by the surveyor, safety officer, fire officer and relevant plant managers. Insurance managers frequently join the tour also.

The quality of fire surveyors in the U.K. (and also in Germany) was appreciated by our interviewees. Some of the U.K. risk managers, however, expressed the thought that the way the physical aspects of a risk were reviewed could be improved. They thought that the management attitude could also be reviewed and advised upon. The risk managers believed that there should be some method whereby the insurance company can measure the safety consciousness, partly through the surveyor, partly through safety records, and should actively encourage such an attitude by direct advice and by appropriate reward through premium reduction.

The surveyor is seen as being an "ambassador" of the insurance company. Thus, any move towards incorporating management audit in the advice of an insurance company should probably be built round the surveyor. However, they are now perceived as being limited entirely to physical aspects and not yet able to deal with the concept of management audit.

Surveyors are accused of not understanding the industrialists' viewpoint and the fact that they spend all their careers in the insurance industry was criticised. Liaison with industry is therefore only through the surveys. The surveyors do not have the experience of having worked in industry, neither do they have the opportunity of free-ranging discussions with risk managers.

Any contacts insurance companies do have with industry are seen as being at top level only, and usually over lunch. For risk managers, it would be better to improve the working-level contact between insurers and insureds. It was suggested by a reinsurance company that presently declining service reflected decreasing personal contact.

Other services, notably on process-inherent risks and liability exposure, should, according to interviewees, be located centrally in insurance companies. Such services would be limited in nature and often be more of the provision of a specialist with whom the specialists of the insureds can discuss the risks and their protection.

Most insurance company executives are "life-long" members of the insurance profession. Similarly, most insurance or risk managers have spent some years with insurance companies and as brokers. There is a sort of insurance "world" with its three components - insurer, insured and brokers - with extensive transfer within that "world", but relatively few newcomers from outside. 
The result of this is, naturally, that the status quo is not frequently questioned and departmentalisation of insurance is still typical.

In this regard, some of our interviewees raised the question of all-risk cover. Their thinking was in terms of seeking cover for loss of goods without distinction as to the cause of the loss. Furthermore, concerning advice and discussion partners for risk protection, a few (exceptional) risk managers emphasised that they want a "total risk" approach, i.e. they wished to break down the traditional departmentalisation of risks, at least with regard to their protection.

Departmentalisation is perceived as adversely affecting the ability of insurance companies to optimise their capabilities in giving risk protection advice. Questioned on their interdepartmental collaboration (e.g. fire with engineering, home with foreign), insurance companies interviewed admitted that there was much room for improvement. Internal human relations problems were unfortunately stated to be commonplace.

Nevertheless, one insurance executive stated, not without vision, that he "dreamt of the day when all the risk protection advisory services in his company were under one hat". Some insurance companies are indeed moving in this direction. follows :

One risk manager expressed the problems associated with an all-risk approach as

- a need for insureds to determine and express the level of risk which they wish to retain ;

- a need for insurers to overcome the traditional departmentalisation in order to offer multi-risk, or preferably all risk, policies :

- the need for both sides to generalise their contact and collaboration to enable new specific and technical problems to be solved, especially in the context of technological risks which are currently the clearest illustration of the problems associated with the whole question of departmentalisation.

Departmentalisation does not concern just the breakdown of risks into different categories. A separation of different parts of the insurance operation may also be excessive in some insurance companies. For example, claims handling is a major source of data that can be fed back to the advisory and tariff setting departments of the insurers. With one or two notable exceptions among the insurers interviewed, claims handling is usually a legal and clerical activity not sufficiently exploited within a given insurance company.

Finally, we quote the words of a French manager who was speaking not just for himself, but as representative of several leading French insureds.

"Satisfactory cover can probably only be obtained if, right from the beginning of commercial negotiations, there is the most close co-operation between the insurers and the insureds which would be maintained throughout the entire negotiations and concerns especially the risk analysis. This would suppose that the insurer has an intimate knowledge of the contractual and technical contraints of his client, but he is fully informed of previous projects of a similar kind, and that he has the opportunity of carrying out controls. This again raises the problem of equipping insurance companies with high quality technicians able to take on 
this analytical type of work. Inevitably this involves a partial dropping of the use of statistics and game theory for the estimation of risk, in favour of an analytical approach case by case."

Perhaps such an approach should be given the title "The Good Partners".

\section{APPENDIX I}

\section{Data on interviewees}

The sample for the following tables was of 50-60 companies.

Table I shows the breakdown of individuals interviewed during the study as a function of whether their responsibilities covered both risk protection and insurance, or just one of these. We were directed to these individuals when we requested permission to meet the person responsible for risk management.

\section{TABLE I - Breakdown of Individuals Interviewed by Responsibilities}

$\begin{array}{lr}\text { Insurance plus risk protection } & 38 \% \quad(13 \% \text { called risk managers }) \\ \text { Insurance only } & 56 \% \\ \text { Risk reduction only } & 6 \% \\ & \frac{600 \%}{100}\end{array}$

The reporting relationship of the insurance or risk managers interviewed was as follows :

TABLE II - Breakdown of Individuals Interviewed by Reporting Relationship

Report to Administrative Director

or Company Secretary $\quad 38 \%$

Report to Financial Director $45 \%$

Report to Legal Department* $\quad 9 \%$

Report to Chairman or Board as a whole $4 \%$

Report to Engineering / Technical Department $\frac{4 \%}{100 \%}$

* encountered only in Germany and Switzerland 
Consequential loss insurance proved to be an area of great fluctuation in attitude from one company to another. The general attitude was, however, positive except in France.

TABLE III - Data on Use of Consequential Loss

Proportion of companies taking " full" C.L.

insurance

$35 \%$

Proportion of companies taking only selective

C.L. insurance

$30 \%$

Proportion of companies that had dropped C.L.

insurance in recent years

$10 \%$

Proportion of companies that were thinking of

taking C.L. insurance up again

$15 \%$

No answer

$10 \%$

Since the role of brokers (one way or the other) is fixed by law or tradition in Continental countries, we consider only the U.K. interviews to be reflective of companies' attitudes towards brokers when given a free choice to use them or not. The sample for the following table is therefore only about 30 companies.

TABLE IV - Breakdown of Use of Brokers Among U.K. Interviewees

Full use of brokers

$38 \%$

Use only where obliged (e.g. Lloyds)

$38 \%$

Selective use, i.e. special agreements

for limited services

$\frac{24 \%}{100 \%}$

Some measure of the degree of self-insurance among interviewees can be gathered from the following table, though it should be noted that most interviewees said they would take more deductibles of the relationship with premium were more favourable.

TABLE V - Data Concerning Deductibles and Captives among Interviewees

Proportion making wide use of deductibles

Proportion with captives

Proportion intending to form captives
$45 \%$

$24 \%$

$13 \%$ 

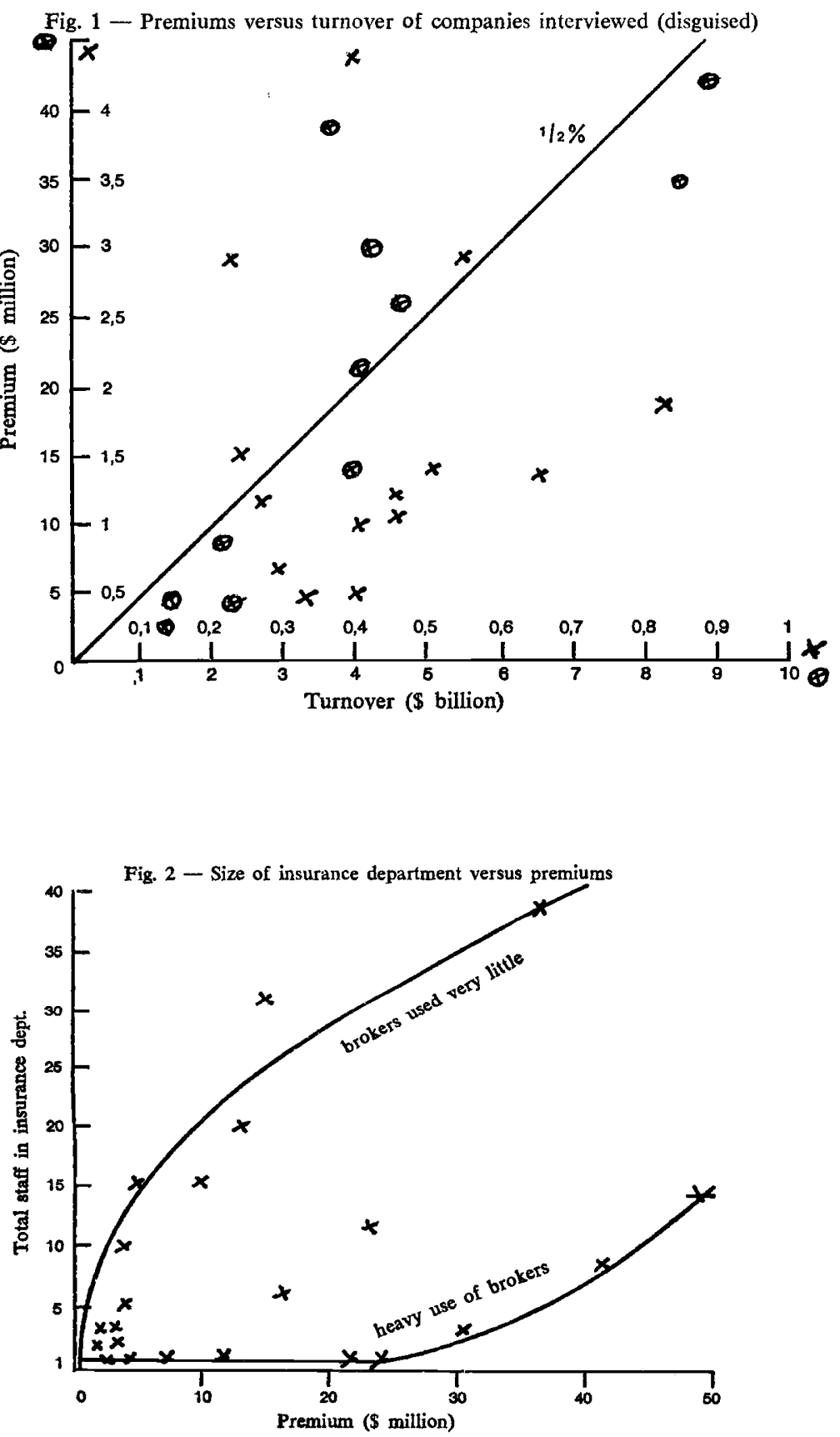


\section{APPENDIX \|}

\section{The dimensions of risk management}

\section{Steps of Risk Management}

- identification of risks

- placing insurance

- evaluation of risks

- loss control

- protection of risks

- contingency planning

- decision on insurance

- loss assessment

- claims handling

Type of Risk

- direct fire

- process inherent

- conventional

- natural disaster

- consequential loss (resultant from fire)

- employer's liability

- public liability

- product liability

- contractors all risks

- security

- commercial espionnage

- fidelity

- transport

- civil commotion

- political ${ }^{10}$

- strikes 10

- war 10

\section{Areas of Decision-making}

- process/equipment design

- building design

- construction material

- sprinklers

- spacing

- separation, etc.

- contracts/legal

- acceptance of liability

- exposure by law

- product design

inspection and correction

- production policy

- of risk reduction devices

- employee screening

- of modification to existing

- labour relations buildings/plant

- human safety

- security service

- line managers

- training/awareness

- record keeping

10 Tend not to be the risk manager's responsibility. 
- production units

- transport function

- offices
- EDP centres

- interface with suppliers/customers and third parties

The following services are listed by the American magazine "Business Insurance" as those " offered by brokers, agents, insurance underwriters, independent risk management consultants and other independent suppliers". The GIRA team has attempted to regroup the list by type of service.

\section{Financial}

Actuarial

Feasibility self-insurance and captives

Risk funding analysis

\section{Placement}

Employee benefit

insurance handling

\section{Administrative}

Accounting
Data precessing
Workers' compensation
administration

\section{Protection}

Asset appraisals

Computer loss runs

Employee benefit planning

Identification/evaluation of risks

Mergers \& acquisitions

Property conservation services

Security programmes
Claims reserves

Insurance audit/review

Tax consulting

Excess, surplus \& special risk placement

Captive management Employee benefit claims handling

Behavioural studies Computer security Employee safety Key manager life insurance anaiysis OSHA compliance Public liability ana'ysis
Employee benefit fund analysis Publications on risk management for financial officers

Insurance handling

Reinsurance

Claims administration Statistical services
Claims audits

Employee benefit analysis

Fire protection

Loss control analysis

Manuals for risk managers

Property Conservation programmes Rish management audits Risk management organisation studies 
Auto claims handling

Loss adjusting

Rehabilitation

programmes
Claims adjusting

Loss control engineering

Rehabilitation services
Claims recovery

Property recovery

(salvage)

\section{APPENDIX III}

\section{Short blbliography}

\section{Manuals and Handbooks}

- Handbook of Risk Management, R. L. Carter and N. A. Doherty Editors, KluwerRarrap Handbooks, London, 1975.

- Practical Risk Management, Ros McIntosh Editor, San Francisco/California, 1974-76.

- Risk Management Manual, Vol. 1 and Vol. 2, Matthew Lenz Jr., The Merritt Company, Santa Monica / California, 1974.

- Risk Management Reports, published by Business Insurance, 740 Rush Street, Chicago, nllinois.

\section{Books and Readings}

- Business Guide to Insurance, by W. L. Catchpole, ed. William Heinemann Ltd, 15 Queen St. Mayfair, London W 1, 1974.

- Cases in Risk Management, by W. Howard, McGraw Hill Inc., New York/USA, 1967.

- Company Insurance Handbook, by AIMIC, ed. Gower Press Limited, Essex/UK, 1973.

- Les Assurances de l'Entreprise, par A. Rosa, ed. J. Delmas et Cie, Paris, 1973.

- Papers in Risk Management, published by Keith Shipton Developments, London.

\section{Textbooks}

- Risk Management in the Business Enterprise, by Mehr \& Hedges, Richard D. Irwin Ed., Illinois/USA, 1964.

- Risk Management and Insurance, by Williams \& Heins, McGraw Hill Insurance Series, 1964/1971.

- Sicherheit durch Versicherung?, by Matthias Haller, Verlag Herbert Lang, Bern, 1975. 